\title{
Effects of Healing Agent on Crack Propagation Behavior in Thermal Barrier Coatings
}

\author{
Soo-Hyeok Jeon, Sung-Hoon Jung, and Yeon-Gil Jung ${ }^{\dagger}$ \\ School of Materials Science and Engineering, Changwon National University, Changwon 51440, Korea \\ (Received July 17, 2017; Revised August 30, 2017; Accepted September 3, 2017)
}

\begin{abstract}
A thermal barrier coating (TBC) with self-healing property for cracks was proposed to improve reliability during gas turbine operation, including structural design. Effect of healing agent on crack propagation behavior in TBCs with and without buffer layer was investigated through furnace cyclic test (FCT). Molybdenum disilicide $\left(\mathrm{MoSi}_{2}\right)$ was used as the healing agent; it was encapsulated using a mixture of tetraethyl orthosilicate and sodium methoxide. Buffer layers with composition ratios of $90: 10$ and $80: 20 \mathrm{wt} \%$, using yttria stabilized zirconia and $\mathrm{MoSi}_{2}$, respectively, were prepared by air plasma spray process. After generating artificial cracks in TBC samples by using Vickers indentation, FCTs were conducted at $1100^{\circ} \mathrm{C}$ for a dwell time of 40 min., followed by natural air cooling for $20 \mathrm{~min}$. at room temperature. The cracks were healed in the buffer layer with the healing agent of $\mathrm{MoSi}_{2}$, and it was found that the thermal reliability of TBC can be enhanced by introducing the buffer layer with healing agent in the top coat.
\end{abstract}

Key words : Thermal barrier coating, Healing agent, Encapsulation, Crack propagation, Thermal reliability

\section{Introduction}

$\mathrm{T}$ o further improve the efficiency of gas turbines used in power generation and propulsion systems, the operating temperatures are steadily increasing. Thermal barrier coatings (TBCs) have been applied to the high temperature components of gas turbines since 1980 to overcome the temperature capacity limit of the superalloy used as the base material in high temperature components of gas turbines. ${ }^{1-3}$ ) TBCs reduce the surface temperature of the high temperature components and increase the engine or gas turbine operating temperature, and related researches have been consistently pursued. ${ }^{4-7)}$ However, TBCs experience thermal and mechanical stresses during heating and cooling processes, resulting in delamination of ceramic top coat caused by the mismatch of thermal and mechanical properties between metallic bond coat and ceramic top coat due to the structural characteristics of TBCs. ${ }^{7-9)}$ Thus, various microstructure designs have been proposed for the top and bond coats to control the thermal conductivity, the elastic modulus, and the coefficient of thermal expansion, which are critical to improve thermal durability of TBCs. Recently, TBCs with self-healing capabilities to prevent rapid delamination and failure during gas turbine operation have been proposed. ${ }^{10,11)}$

Generally, delamination or failure in TBC is created with crack propagation and coalescence within $100 \pm 50 \mu \mathrm{m}$ of

\footnotetext{
${ }^{\dagger}$ Corresponding author : Yeon-Gil Jung

E-mail : jungyg@changwon.ac.kr

Tel : +82-55-213-3712 Fax : +82-55-262-6486
}

the interface between the top and bond coats. Therefore, a healing agent was added to inhibit crack propagation and/ or heal cracks created during gas turbine operation, and to prevent rapid delamination and failure within $150 \mu \mathrm{m}$ from the interface. ${ }^{12-14)}$ Since the high temperature components of gas turbines are generally used in high temperature environments, the healing agent has to be solid and should have mobility to fill the cracks and inhibit crack propagation in the temperature. Also, the healing agent in the crack has to solidify through subsequent chemical reactions. A representative healing agent is molybdenum disilicide, $\mathrm{MoSi}_{2} .{ }^{15,16)}$ The self-healing mechanism of TBC including $\mathrm{MoSi}_{2}$ produces $\mathrm{SiO}_{2}$ and $\mathrm{MoO}_{3}$ through the chemical reaction below; this is related to the oxidation reaction of $\mathrm{MoSi}_{2}$. In other words, when a crack propagates and meets the healing agent, a chemical reaction occurs after the materials come into contact with oxygen. ${ }^{17,18)}$

$$
2 \mathrm{MoSi}_{2}(\mathrm{~s})+7 \mathrm{O}_{2}(\mathrm{~g}) \rightarrow 2 \mathrm{MoO}_{3}(\mathrm{~g})+4 \mathrm{SiO}_{2}(\mathrm{~s})
$$

Since the mole volume of silica $\left(\mathrm{SiO}_{2}\right)$ (2 mole volume) is greater than the mole volume of $\mathrm{MoSi}_{2}$ (1 mole volume), $\mathrm{SiO}_{2}$ reacts with zirconia $\left(\mathrm{ZrO}_{2}\right)$ and produces zircon $\left(\mathrm{ZrSiO}_{4}\right)$, and the gaseous $\mathrm{MoO}_{3}$ generated from the reaction exits through pores in the top coat. Crack propagation will be inhibited because the toughness of the formed zircon is greater than that of YSZ. ${ }^{19)}$ On the other hand, $\mathrm{MoSi}_{2}$ exhibits low strength at high temperatures and low toughness, making its application as a TBC material limited, and the healing capability could be lost due to early oxidation of $\mathrm{MoSi}_{2}$ particles. ${ }^{20,21)}$ Thus, encapsulation of the healing agent was proposed as a solution to prevent the early oxida- 
tion reaction and maintain the self-healing capability of $\mathrm{MoSi}_{2}$ particles; it was reported in the literature that encapsulation using alumina prevented the oxidation reaction of $\mathrm{MoSi}_{2}{ }^{22)}$

In this study, a top coat layer with a buffer layer containing the self-healing agent was designed and its microstructure was optimized. Also, furnace cyclic test (FCT) was conducted in a high temperature environment of $1100^{\circ} \mathrm{C}$. To investigate the resistance to crack propagation at the buffer layer with the healing agent, a novel thermal barrier structure was proposed that can guarantee the reliability of the TBC.

\section{Experimental Procedure}

\subsection{Healing Agent and Encapsulation}

The healing agent used for fabricating the TBC with selfhealing capability was $\mathrm{MoSi}_{2}$ (Sigma-Aldrich Korea, Yongin, Korea), which was encapsulated with a liquid precursor to prevent early oxidation. Tetraethyl orthosilicate (TEOS, Sigma-Aldrich Korea, Yongin, Korea) and sodium methoxide (NaOMe, Sigma-Aldrich Korea, Yongin, Korea) were used as the liquid precursor. Encapsulation of the healing agent was conducted using each precursor and the precursor mixed together at specific weight ratios; TEOS, NaOMe, and isobutyl alcohol at the weight ratio of $38: 56: 6$ to $\mathrm{MoSi}_{2}$ powder of $250 \mathrm{~g}$. The encapsulated $\mathrm{MoSi}_{2}$ powder was dried at $80^{\circ} \mathrm{C}$ for $24 \mathrm{~h}$, followed by dry ball-milling for $24 \mathrm{~h}$ using $\mathrm{ZrO}_{2}$ balls.

\subsection{Preparation of Specimen}

Before fabricating the TBC specimen, the yttria-stabilized $\mathrm{ZrO}_{2}$ (8YSZ, Sigma-Aldrich Korea, Yongin, Korea) and the healing agent $\left(\mathrm{MoSi}_{2}\right)$ were mixed at two weight ratios of 90 : 10 and $80: 20$, and then the circular specimens (composite specimen) of $10 \mathrm{~mm}$ diameter were prepared at $13 \mathrm{MPa}$ in order to investigate the reactivity between the $8 \mathrm{YSZ}$ and the healing agent, and their self-healing capability. For investigating the oxidation behavior of the healing agent only, the specimen was prepared using the healing agent with same condition. At that time, the healing agent was encapsulated with each precursor and the mixed precursor. The prepared specimens were heated to $1300^{\circ} \mathrm{C}$ at a rate of $5^{\circ} \mathrm{C}$ per min. for a dwell time of $5 \mathrm{~h}$ under an argon atmosphere. An Ni alloy (Nimonic 263, a nominal composition of Ni-20Cr-20Co-5.9Mo-0.5Al-2.1Ti-0.4Mn-0.3Si-0.06C, in wt\%, Thyssen Krupp VDM, Germany) was used as a base material (substrate) for the TBC; the diameter and thickness of the specimens were $25.4 \mathrm{~mm}$ and $3 \mathrm{~mm}$, respectively. Before forming the bond coat, the base substrate was sand-blasted using alumina powder of 60 mesh; the high velocity oxygen fuel (HVOF) method with AMDRY 9954 (Oerlikon Metco AG, nominal composition of Co-32Ni-21Cr$8 \mathrm{Al}-0.5 \mathrm{Y}$ in wt.\% and particle size of $11-63 \mu \mathrm{m}$ ) powder was used to form thickness of approximately $300 \pm 50 \mu \mathrm{m}$. Using the air plasma spray (APS) method, the buffer with the healing agent was introduced at the interface between the bond and top coats where cracking and delamination are mainly created. For the buffer layer, 204C-NS (Oerlikon Metco AG, Switzerland, 8 wt. $\% \mathrm{Y}_{2} \mathrm{O}_{3}$ doped in $\mathrm{ZrO}_{2}$, particle size of $45-140 \mu \mathrm{m}$ ) and encapsulated healing agent $\mathrm{MoSi}_{2}$ were mixed at weight ratios of $90: 10$ and $80: 20$, and then the buffer layer with a thickness of $150 \pm 50 \mu \mathrm{m}$ was coated. The top coat was formed by the APS method using the 204C-NS powder. The structures of TBCs fabricated in this study is shown in Fig. 1, in which it can be seen that the TBCs with and without the buffer layer had the top coat thicknesses of 450 and $600 \mu \mathrm{m}$, respectively.

\subsection{Evaluation and Analysis of Healing Behavior}

In order to investigate the crack healing behavior in the composite specimens a Vickers hardness tester (HM-114, Mitutoyo Corp., Japan) was used to create an artificial crack on the surface of heat-treated specimen in the $90^{\circ}$
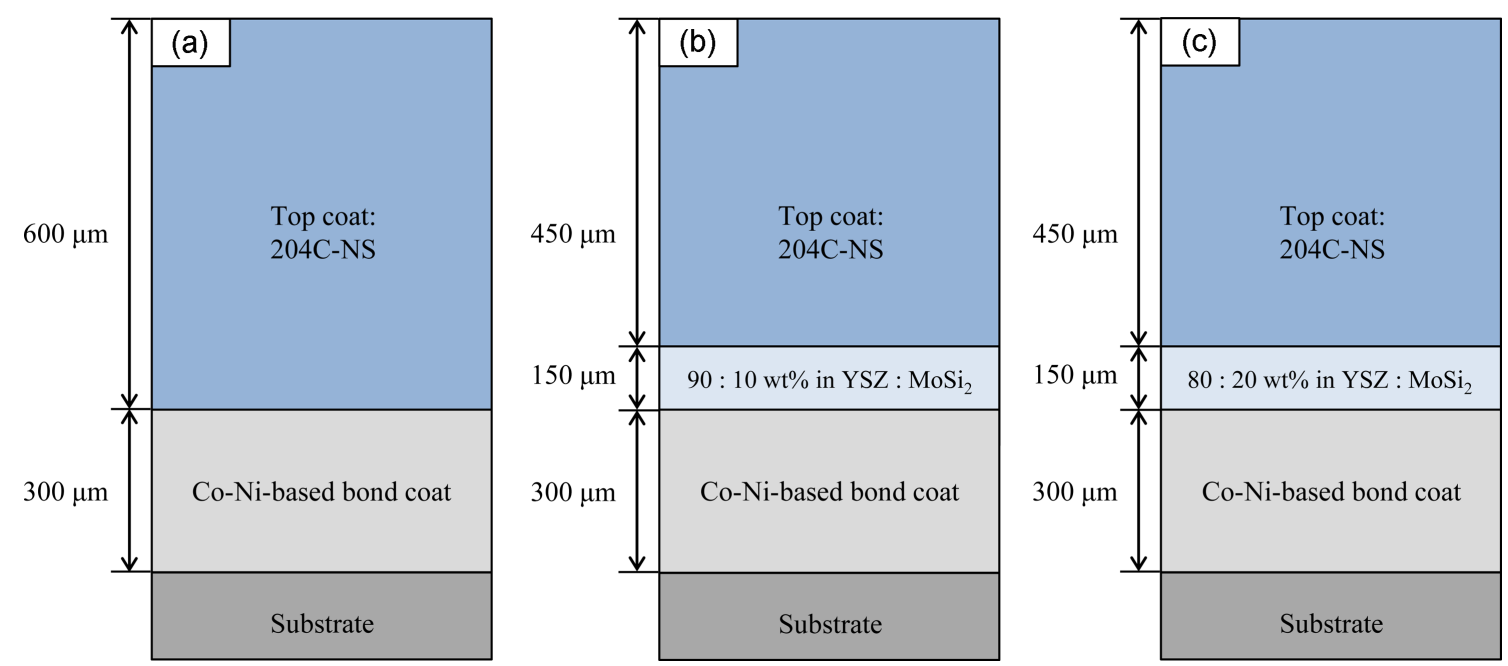

Fig. 1. Schematic diagram for TBCs used in this study. 


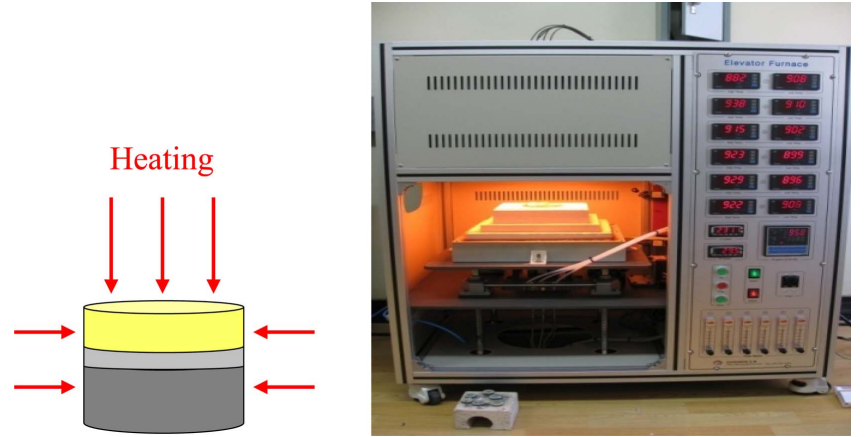

Fig. 2. Photos of FCT apparatus.

direction with a load of $100 \mathrm{~N}$. To investigate the crack healing behavior of the specimen with the artificial crack, the FCT was carried out which is one of the universal evaluation methods for thermal stability of TBC, with heating for $40 \mathrm{~min}$. at $1100^{\circ} \mathrm{C}$ and cooling for $20 \mathrm{~min}$. as one cycle. Fig. 2 shows the FCT equipment used in this study. Also, an isothermal oxidation test was carried out for $100 \mathrm{~h}$ at $1100^{\circ} \mathrm{C}$ to observe the crack healing behavior. Changes in the surface morphology of the powders coated with each precursor were observed before and after heat treatment, using scanning electron microscope (SEM, JEOL Model JSM-5610, Japan). Additionally, the cross-sectional microstructure of the composite and TBC specimens before and after the FCT was observed using SEM after fixing each specimen with epoxy resin, followed by polishing using silicon carbide abrasive paper and diamond pastes with particle diameters of $3 \mu \mathrm{m}$ and $1 \mu \mathrm{m}$. The hardness values of the top and bond coats were measured using a Vickers hardness tester with a load of $3 \mathrm{~N}$. Ten indentations were performed to determine the standard deviation of each value. All indentations were conducted at room temperature according to the "Vickers Indentation Hardness of Advanced Ceramics (ASTM C132703)" standard. An energy dispersive spectrometer (EDS, Oxford Instruments, Oxford, UK) was used to analyze the composition variation of the healing agent after the FCT.

\section{Results and Discussion}

\subsection{Encapsulation of Healing Agent}

The precursor used in the encapsulation process became glass phase during heat treatment, which prevents the oxidation of the healing agent. For the successful implementation of this role, a uniform coating for the healing agent has to be obtained; a liquid precursor was used to attain such uniformity. Three kinds of precursor, such as TEOS, $\mathrm{NaOMe}$, and their mixture (TEOS $+\mathrm{NaOMe}$ ), were employed in the encapsulation process, which are thought to exhibit fluidity at the TBC application temperature (approximately $1100^{\circ} \mathrm{C}$ ), and to be able to establish and maintain the coating layer. Fig. 3 shows the results of heat treatment for the specimens prepared using healing agent only encapsulated with each precursor and the mixed precursor. Fig. 3(a-1) shows the encapsulation results when using only the Si liquid precursor, TEOS. As can be observed in Fig. 3(a-2), the specimen did not maintain its shape after heat treatment due to oxidation or early reaction. Fig. 3(b) shows the encapsulation and heat treatment results obtained using the $\mathrm{Na}$ liquid precursor, $\mathrm{NaOMe}$; it can be observed that some specimens experienced a shape deformation due to early reactions. Meanwhile, Fig. 3(c) shows the encapsulation results when using the precursor mixed with TEOS, NaOMe, and isobutyl alcohol at the weight ratio of $38: 56: 6$, showing a sound condition after heat treatment. This result was considered to be due to the formation of glass phase with fluidity at the relatively low temperature, and the increase of the coating uniformity and efficiency for the healing agent. ${ }^{23)}$

\subsection{Healing Behavior in Composite Specimen}

Before establishing the TBC, the fabricated composite specimen was heat-treated under the argon atmosphere to determine the optimal mixture ratio of the feedstock powder and the healing agent, and the encapsulation composition
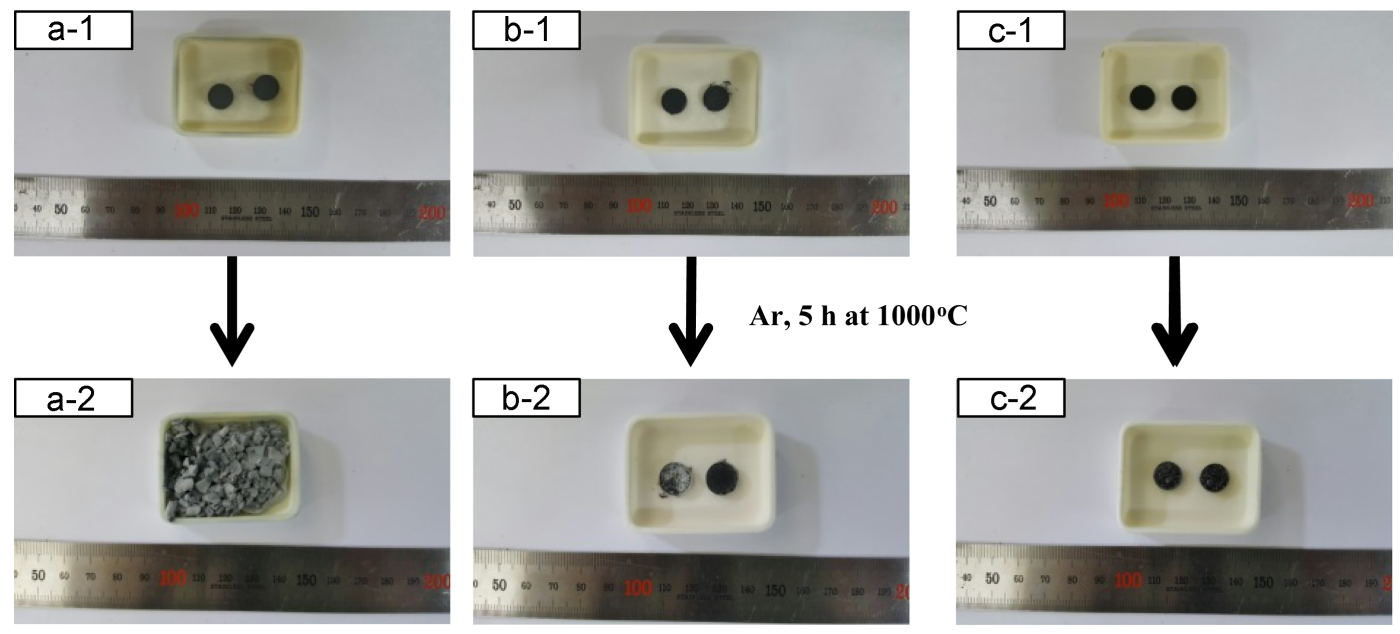

Fig. 3. Thermal behavior of composites with encapsulation composition: (a) TEOS, (b) NaOMe, and (c) TEOS + NaOMe. Each number indicates thermal behavior before and after heat treatment, respectively. 

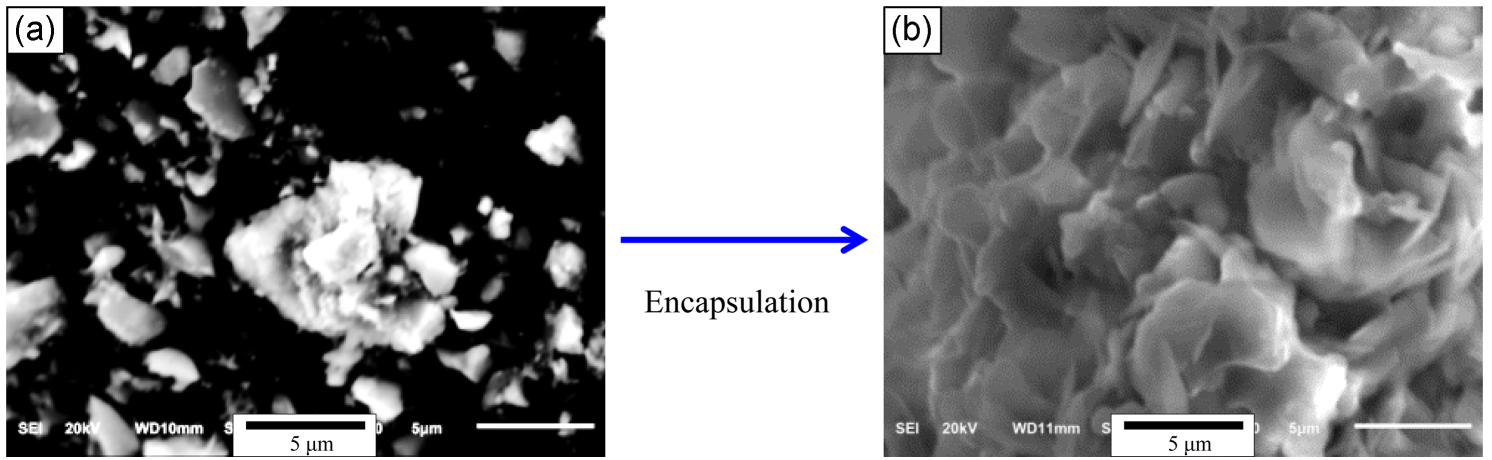

Fig. 4. Highly magnified microstructure of $\mathrm{MoSi}_{2}$ powder before and after encapsulation with TEOS + NaOMe: (a) as-prepared powder and (b) encapsulated powder.

for the healing agent. The composite specimen with the nonencapsulated healing agent was heat-treated at $1300^{\circ} \mathrm{C}$, showing the oxidation and volume changes due to the early reaction of the healing agent $\left(\mathrm{MoSi}_{2}\right)$ (results were not shown in here). Meanwhile, the composite specimens with 10 and 20 wt\% encapsulated healing agent maintained their integrity even after heat treatment at $1300^{\circ} \mathrm{C}$. Fig. 4 shows the numerous pores in the microstructure before encapsulation, while the microstructure after encapsulation revealed a fine membrane (coating layer) surrounding the healing agent $\left(\mathrm{MoSi}_{2}\right)$, indicating the establishment of encapsulation. Therefore, it was observed that the encapsulation process prevented the early reaction of the healing agent, and it was thought that cracks formed in the composite and TBC specimens can be healed at high temperatures and/or crack propagation will be inhibited.

The FCT was conducted after creating an artificial crack on the surface of composite specimen heat-treated at $1300^{\circ} \mathrm{C}$ under the argon atmosphere, as shown in Fig. 5. The area of the crack containing the healing agent experienced a reaction between the healing agent and the crack during the FCT (after 20 and 40 cycles), which suppressed further crack propagation. It can be seen that the area of the propagated crack and reacted healing agent enlarged as the ther-
Table 1. Result of EDS Analysis for Healing Agent in TBC after FCT

\begin{tabular}{ccc}
\hline \multirow{2}{*}{ Element } & \multicolumn{2}{c}{ Position A } \\
\cline { 2 - 3 } & wt\% & atomic \% \\
\hline $\mathrm{O}$ & 40.98 & 74.89 \\
$\mathrm{Na}$ & 6.03 & 7.68 \\
$\mathrm{Si}$ & 0.95 & 0.99 \\
$\mathrm{Y}$ & 2.60 & 0.85 \\
$\mathrm{Zr}$ & 33.34 & 10.69 \\
$\mathrm{Mo}$ & 16.10 & 4.91 \\
Total: & 100.00 & 100.00 \\
\hline
\end{tabular}

mal fatigue cycle increased. Composition analysis for the area marked with a dotted circle in Fig. 5(a), which is the healing agent reacting with YSZ, was performed and the results are detailed in Table 1 . The composition analysis showed that $\mathrm{MoO}_{3}$ and $\mathrm{SiO}_{2}$ were produced from the decomposition and oxidation of $\mathrm{MoSi}_{2}$ at high temperature, respectively, and it can be predicted that $\mathrm{ZrSiO}_{4}$ was produced. ${ }^{17)}$ On the other hand, the produced $\mathrm{ZrSiO}_{4}$ suppressed crack propagation due to the higher toughness than YSZ, result-
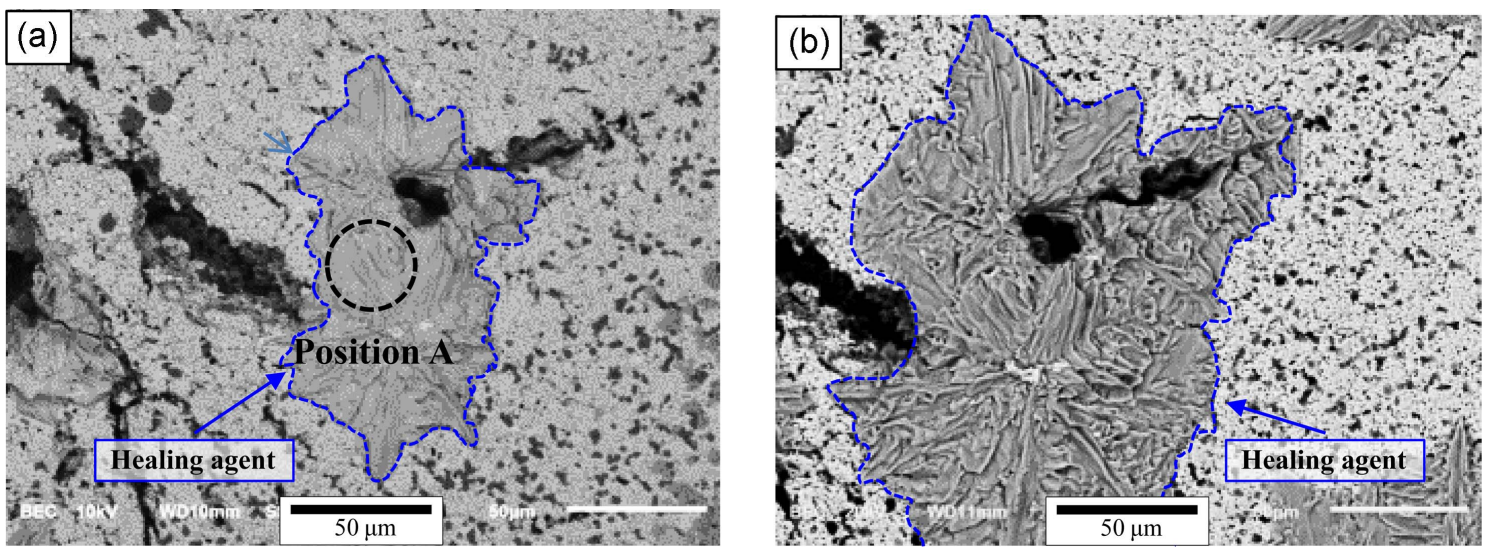

Fig. 5. Cross-sectional microstructure of composite specimen with 20 wt\% encapsulated healing agent after FCTs: (a) 20 cycles and (b) 40 cycles. 

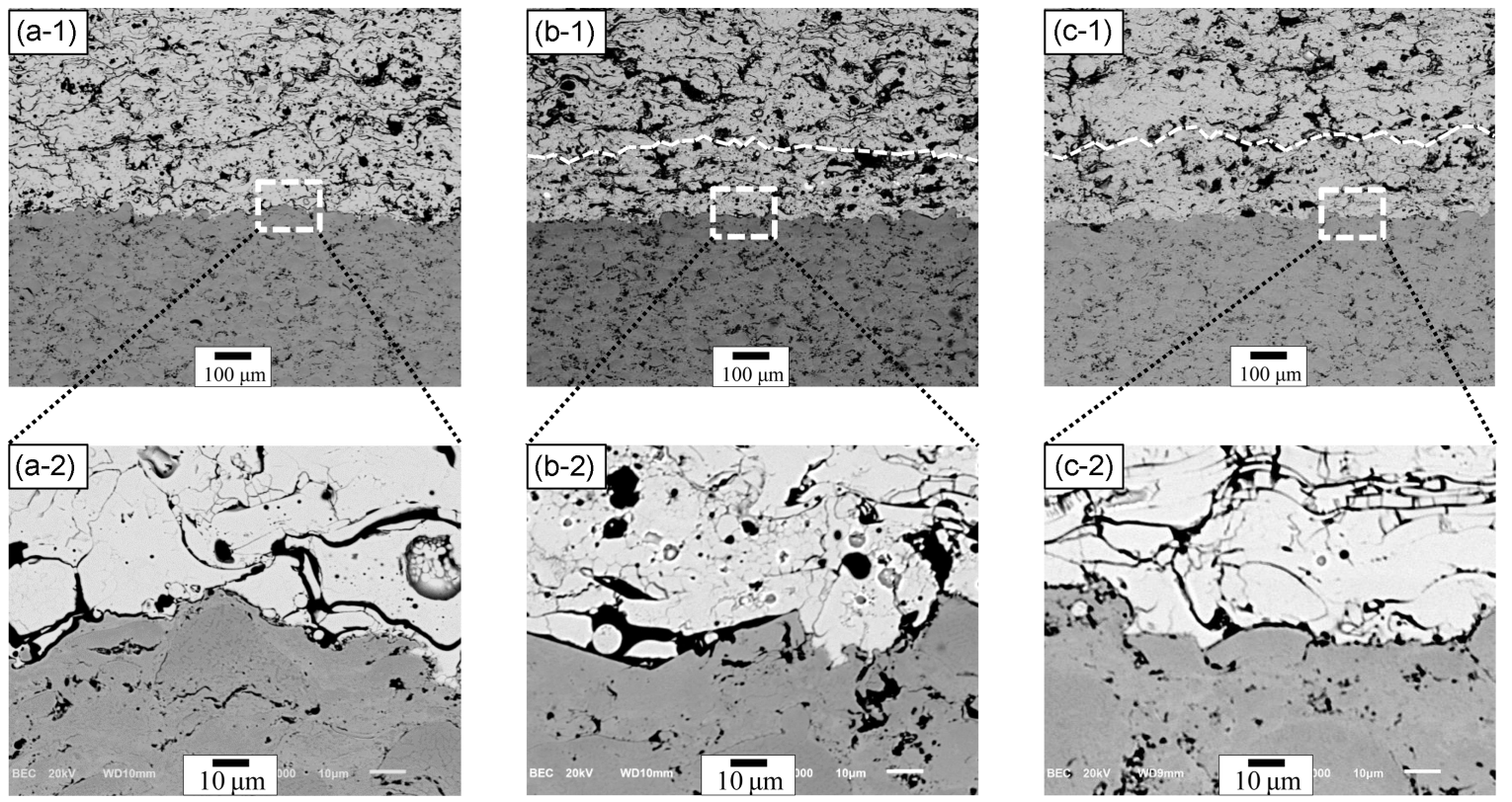

Fig. 6. Cross-sectional microstructure of as-prepared TBCs: (a) without buffer layer and healing agent, (b) with buffer layer with $\mathrm{MoSi}_{2}$ of $10 \mathrm{wt} \%$, and (c) with buffer layer with $\mathrm{MoSi}_{2}$ of $20 \mathrm{wt} \%$. Each number indicates microstructure and highly magnified interface microstructure, respectively.

ing in enhancing the lifetime of the TBC.

\subsection{Formation of TBC and Its Healing Behavior}

Figure 6 shows the cross-sectional microstructures of TBCs depending on the presence of the buffer layer with the encapsulated healing agent. The TBC, regardless of the presence of the buffer layer, revealed a sound microstructure with no cracks or delamination at the interface. Since delamination or failure of TBC can be observed according to the crack propagation at $100 \pm 50 \mu \mathrm{m}$ from the interface between the top and bond coats, the buffer layer with the healing agent was well established according to the design at about $150 \mu \mathrm{m}$ from the interface; the interface between the first layer (buffer layer) and the second layer in the top coat is marked with a dotted line. Fig. 7 shows the microstructure of the TBC with the buffer layer before and after isothermal oxidation test for $10 \mathrm{~h}$ after creating an artificial crack on the cross-section of the TBC. The buffer layer was prepared using the mixed feedstock powder of the $204 \mathrm{C}-\mathrm{NS}$ powder and healing agent at the $90: 10$ weight ratio. Although the reaction between the crack formed around the healing agent and the healing agent was not observed before the isothermal oxidation test, the healing agent included in the TBC reacted with the crack and inhibited the crack propagation after the isothermal oxidation test. However oxidation of the healing agents was observed even for parts without cracks. To improve the thermal durability of the TBC, oxidation has to be prevented by using the encapsulated healing agent; further research in this direction is necessary. Especially, further research to identify new materials for the encapsulation of $\mathrm{MoSi}_{2}$, or new healing agents with low melting points and high fluidity, is nec-
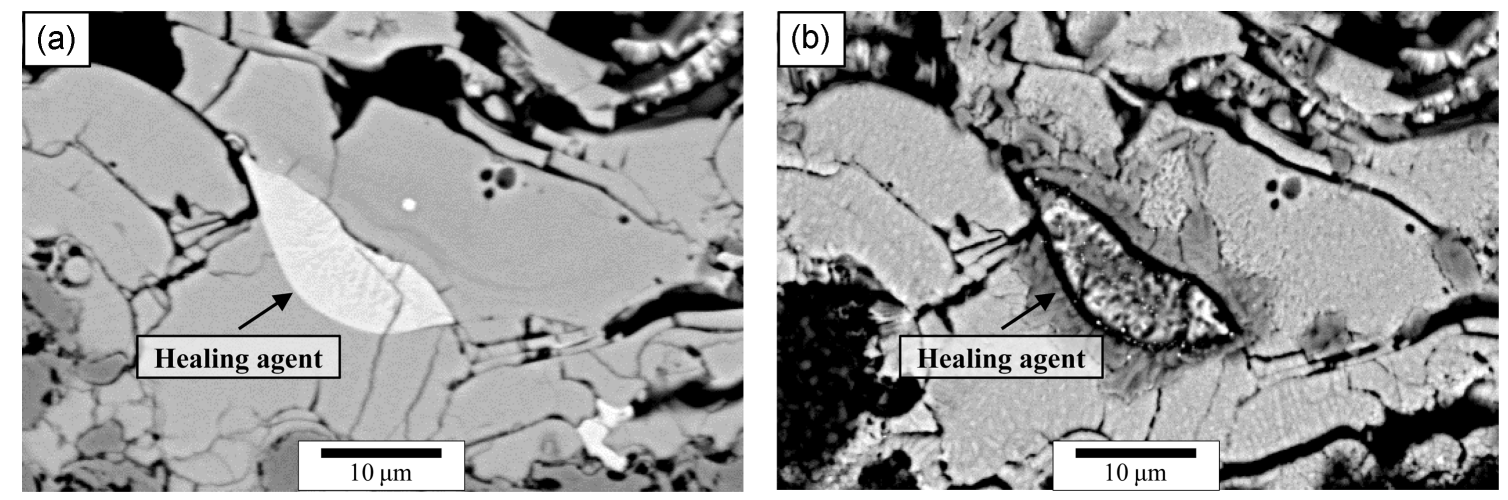

Fig. 7. Cross-sectional microstructure before and after isothermal oxidation test: (a) as-prepared status and (b) after isothermal oxidation test for $10 \mathrm{~h}$. 


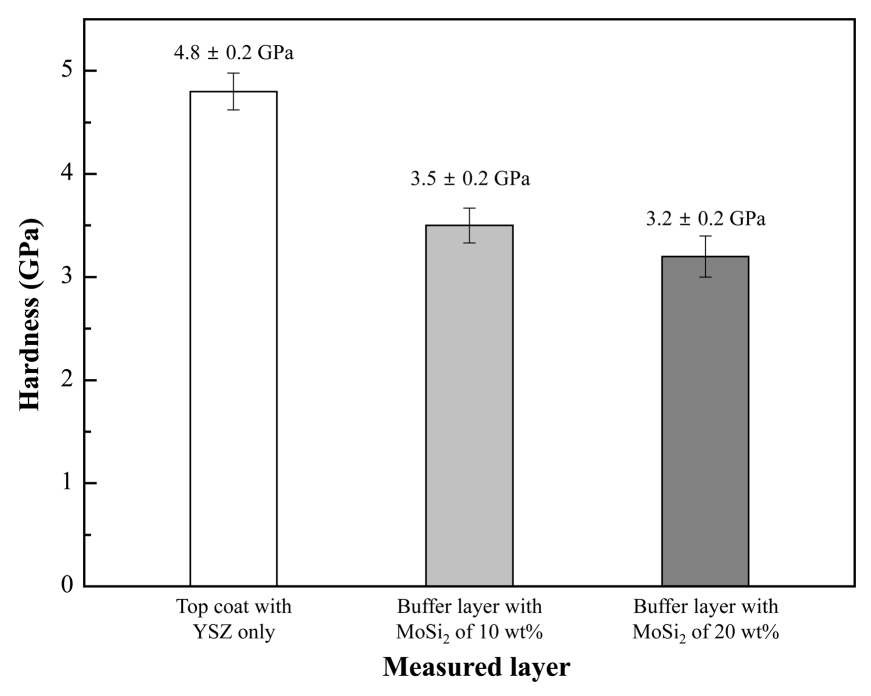

Fig. 8. Hardness values of as-prepared TBCs obtained by Vickers indentation.

essary for application to next generation TBC utilizing rare earth resources.

\subsection{Hardness Property}

Hardness, which is one of mechanical properties, was measured at identical points for the buffer layer with the healing agent and for the top coats without the healing agent; the results are shown in Fig. 8. First, the hardness values of each buffer layer with 10 and $20 \mathrm{wt} \%$ healing agent were determined to be $3.5 \pm 0.2$ and $3.2 \pm 0.2 \mathrm{GPa}$, respectively, while the hardness of the top coat without the healing agent showed a relatively high value of $4.8 \pm 0.2$ GPa. It was determined through the hardness values that the healing agent was uniformly distributed. The reduction in hardness according to the increase of healing agent content was thought to be due to the oxidation and decomposition of the healing agent $\left(\mathrm{MoSi}_{2}\right)$ into $\mathrm{SiO}_{2}$ and $\mathrm{MoO}_{3}$, respectively, during the coating process, increasing the porosity within the coating with leaving the decomposed $\mathrm{MoO}_{3}$ through the pores and ultimately leading to a decrease of the hardness values. ${ }^{24)}$ However, the buffer layer with the healing agent exists in the interior (within $100 \pm 50$ $\mu \mathrm{m}$ from the interface between the bond and top coats), there was no direct impact on the wear resistance of the TBC. The decrease in hardness is a result of pore formation in the buffer layer, the elastic modulus will be decreased which is thought to be able to increase the stress capacity and deformation resistance, and improve the lifetime of the TBC. In the future, control of the healing agent content and species, processing parameter, and encapsulation composition should be expected to enable TBC lifetime enhancement.

\section{Conclusions}

In this study, a thermal barrier coating (TBC) with self- healing capability through a buffer layer was fabricated and its crack healing behavior was investigated through furnace cyclic test (FCT) and isothermal oxidation test, and the following conclusions were obtained.

1) In order to prevent the early reaction of the healing agent $\left(\mathrm{MoSi}_{2}\right)$, the healing agent was encapsulated using the precursors of TEOS, NaOMe, and a mixture of the two precursors. After heat treatment, the early reaction or oxidation of the healing agent was effectively prevented through encapsulation with the mixed composition.

2) FCT for the composite with the encapsulated healing agent showed that crack propagation was suppressed.

3) Although the isothermal oxidation test for the TBC with the buffer layer including the healing agent showed that crack propagation was inhibited by the reaction between the crack and the healing agent, oxidation of the healing agent was observed for areas without cracks.

4) The hardness value of the TBC exhibited a decreasing trend with increasing the healing agent content. The decrease in hardness for the buffer layer with the healing agent is expected to improve TBC lifetime by decreasing the elastic modulus at the interface and increasing the stress capacity and deformation resistance.

\section{Acknowledgements}

This research was supported by Changwon National University in 2017-2018.

\section{REFERENCES}

1. S. W. Myoung, S. S. Lee, H. S. Kim, M. S. Kim, Y. G. Jung, S. I. Jung, T. K. Woo, and U. Paik, "Effect of Post Heat Treatment on Thermal Durability of Thermal Barrier Coatings in Thermal Fatigue Tests," Surf. Coat. Technol., 215 46-51 (2013).

2. P. Richer, M. Yandouzia, L. Beauvais, and B. Jodoin, "Oxidation Behaviour of CoNiCrAlY Bond Coats Produced by Plasma, HVOF and Cold Gas Dynamic Spraying," Surf. Coat. Technol., 204 [24] 3962-74 (2010).

3. B. Rajasekaran, G. Mauer, and R. Vaßen, "Enhanced Characteristics of HVOF-Sprayed MCrAlY Bond Coats for TBC Applications," J. Therm. Spray Technol., 20 [6] 120916 (2011).

4. A. G. Evans, D. R. Mumm, J. W. Hutchinson, G. H. Meier, and F. S. Pettit, "Mechanisms Controlling the Durability of Thermal Barrier Coatings," Prog. Mater. Sci., 46 [5] 505-53 (2001).

5. D. R. Clarke, M. Oechsner, and N. P. Padture, "ThermalBarrier Coatings for More Efficient Gas-turbine Engines," MRS Bull., 37 [10] 891-98 (2012).

6. D. R. Clarke and C. G. Levi, "Materials Design for the Next Generation Thermal Barrier Coatings," Annu. Rev. Mater. Res., 33 [1] 383-417 (2003).

7. R. A. Miller, "Current Status of Thermal Barrier Coatings-An Overview," Surf. Coat. Technol., 30 [1] 1-11 (1987).

8. E. Ercenk, U. Sen, and S. Yilmaz, "Structural Characteri- 
zation of Plasma Sprayed Basalt-SiC Glass-Ceramic Coatings," Ceram. Int., 37 [3] 883-89 (2011).

9. S. Das, A. K. Mukhopadhyay, S. Datta, G. C. Das, and D. Basu, "Hard Glass-Ceramic Coating by Microwave Processing," J. Eur. Ceram. Soc., 28 [4] 729-38 (2008).

10. T. A. Dobbins, R. Knight, and M. J. Mayo, "HVOF Thermal Spray Deposited $\mathrm{Y}_{2} \mathrm{O}_{3}$-Stabilized $\mathrm{ZrO}_{2}$ Coatings for Thermal Barrier Applications," J. Therm. Spray Technol., 12 [2] 214-25 (2003).

11. N. P. Padture, M. Gell, and E. H. Jordan, "Thermal Barrier Coatings for Gas-Turbine Engine Applications," Science, 296 [5566] 280-84 (2002).

12. W. G. Sloof, S. R. Turteltaub, A. L. Carabat, Z. Derelioglu, S. A. Ponnusami, and G. M. Song, "Crack Healing in Yttria Stabilized Zirconia Thermal Barrier Coatings," pp. 219-27 in Pioneering Research in Netherlands, Delft University Press, 2015.

13. W. R. Chen, X. Wu, B. R. Marple, R. S. Lima, and P. C. Patnaik, "Pre-Oxidation and TGO Growth Behaviour of an Air-Plasma-Sprayed Thermal Barrier Coating," Surf. Coat. Technol., 202 [16] 3787-96 (2008).

14. F. Nozahic, D. Monceau, and C. Estournès, "Thermal Cycling and Reactivity of a $\mathrm{MoSi}_{2} / \mathrm{ZrO}_{2}$ Composite Designed for Self-Healing Thermal Barrier Coatings," Mater. Des., 94 444-48 (2016).

15. S. D. Mookhoek, H. R. Fischer, and S. van der Zwaag, "A Numerical Study into the Effects of Elongated Capsules on the Healing Efficiency of Liquid-Based Systems," Comput. Mater. Sci., 47 [2] 506-11 (2009).

16. Z. Derelioglu, A. L. Carabat, G. M. Song, S. van der Zwaag, and W. G. Sloof, "On the Use of B-Alloyed $\mathrm{MoSi}_{2}$ Particles as Crack Healing Agents in Yttria Stabilized Zirconia Thermal Barrier Coatings," J. Eur. Ceram. Soc., 35 [16] 4507-11 (2015).

17. A. A. Sharif, "High-Temperature Oxidation of $\mathrm{MoSi}_{2}, " J$. Mater. Sci., 45 [4] 865-70 (2010).

18. M. J. Meijerink, "Coating of $\mathrm{MoSi}_{2}$ Healing Particles for Self-Healing Thermal Barrier Coatings," in MS Thesis, Delft University of Technology, Delft, 2015.

19. M. Erfanmanesh, S. R. Bakhshi, M. Khajelakzay, and M. Salekbafghi, "The Effect of Argon Shielding Gas at Plasma Spray Process on the Structure and Properties of $\mathrm{MoSi}_{2}$ Coating," Ceram. Int., 40 [3] 4529-33 (2014).

20. M. Kilo, C. Argirusis, G. Borchardt, and R. A. Jackson, "Oxygen Diffusion in Yttria Stabilized Zirconia-Experimental Results and Molecular Dynamics Calculations," Phys. Chem. Chem. Phys., 5 [11] 2219-24 (2003).

21. Z. Yao, J. Stiglich, and T. S. Sudarshan, "Molybdenum Silicide Based Materials and Their Properties," J. Mater. Eng. Perform., 8 [3] 291-304 (1999).

22. H. Heuer, "Oxygen and Aluminum Diffusion in $\alpha-\mathrm{Al}_{2} \mathrm{O}_{3}$ : How Much Do We Really Understand?," J. Eur. Ceram. Soc., 28 [7] 1495-507 (2008).

23. E. H. Kim, W. R. Lee, Y. G. Jung, and C. S. Lee, "A New Binder System for Preparing High Strength Inorganic Molds in Precision Casting," Mater. Chem. Phys., 126 [1] 344-51 (2011).

24. A. Portinha, V. Teixeira, J. Carneiro, J. Martins, M. F. Costa, R. Vassen, and D. Stoever, "Characterization of Thermal Barrier Coatings with a Gradient in Porosity," Surf. Coat. Technol., 195 [2] 245-51 (2005). 